\title{
Hybrid percutaneous atrial septal defect closure with surgical occluder fixation
}

\author{
Roman Przybylski', Jędrzej Reczuch², Maciej Bochenek', Tomasz Witkowski2, ${ }^{2}$, Krzysztof Reczuch²,4, \\ Wiktor Kuliczkowski, 3
}

'Clinic of Cardiac Transplantation and Mechanical Circulatory Support, Wroclaw Medical University, Wrocław, Poland

Department of Heart Diseases, University Hospital, Wrockaw, Poland

${ }^{3}$ Department of Cardiology, Wroclaw Medical University, Wrocław, Poland

${ }^{4}$ Department of Heart Diseases, Wroclaw Medical University, Wrocław, Poland

\author{
Correspondence to: \\ Jędrzej Reczuch, MD \\ Department of Heart \\ Diseases, \\ University Hospital, \\ Borowska 213, \\ 55-556 Wrocław, \\ phone: +48 717364257 , \\ e-mail: \\ jedrzej.reczuch@gmail.com \\ Copyright by the Author(s), \\ 2021 \\ Kardiol Pol. 2021; \\ 79 (10): 1157-1158. \\ DOI: 10.33963/KP.a2021.0078 \\ Received: \\ April 28, 2021 \\ Revision accepted: \\ July 26, 2021 \\ Published online: \\ July 28, 2021
}

A 62-year-old woman with a history of dyspnea in ordinary activities was admitted for an atrial septal defect (ASD) type 2 treatment. Transthoracic echocardiography revealed diastolic dysfunction of the left ventricle, right heart enlargement, atrial septal aneurysm, and an atrial septal defect with a left-to-right shunt. The Qp:Qs was 1.7. The probability of pulmonary hypertension was moderate. The transesophageal echocardiogram showed a $17 \times 10 \mathrm{~mm}$ ostium secundum ASD with a left-to-right shunt, an atrial septal aneurysm protruding into the right atrium, a deficiency of the superior vena cava rim and the short aortic rim (Supplementary material, Video S1 - ASD). The inferior vena cava (IVC) rim was limp. Following the European Society of Cardiology recommendations, this morphology is an indication to surgical repair; however, due to the patient's moderate frailty, the Heart Team chose device closure instead, as it seemed technically suitable $[1,2]$.

The pressures in the right heart were assessed: right ventricle $-27 / 4$ mean $7 \mathrm{~mm}$ $\mathrm{Hg}$, pulmonary artery - 18/8 mean $13 \mathrm{~mm}$ $\mathrm{Hg}$, mean wedge pressure $8 \mathrm{~mm} \mathrm{Hg}$, transpulmonary gradient $5 \mathrm{~mm} \mathrm{Hg}$, cardiac output $5.5 \mathrm{l} / \mathrm{min}$, pulmonary vascular resistance 0.9 Wood units. After the "stop-flow" technique balloon sizing, the 20-mm "Cera" occluder was successfully placed. Despite the rim deficien$c y$, the device was stable during the tug test. However, due to the atrial septum aneurysm, the IVC rim was loose, providing poor support for the device with a risk of detachment. The device was removed, and the concept of hybrid intervention came up.
Under general anesthesia, a lateral thoracotomy and an opening of the pericardial sac were performed. The Lifetech Cera 20-mm occluder was delivered through the right femoral vein. Both discs were expanded at optimal positions. Compression of the right atrium wall by forceps localized in transesophageal echocardiography pointed where the suture should be placed. Simultaneously, the cardiologist pulled the device to an optimized position for suturing. The right atrial disc was fixated to the limp IVC rim by a single suture placed by the surgeon through the right atrium wall (Supplementary material, Video S2 - device suturing). A standard tug test was performed (Supplementary material, Video S3 - tug test). The device had efficient support from the inferior-posterior side. The occluder was then released (Supplementary material, Video $S 4$ - device detachment from delivery cable). The pericardial sac and the thoracic wall were closed. The patient was extubated the same day. Transthoracic echocardiography performed the next day showed an insignificantly small residual shunt (Supplementary material, Video S5 - final result). The patient was discharged after 8 days.

To the best of our knowledge, it was the first case of a hybrid percutaneous ASD closure. This unique approach allowed us to perform device closure in a patient that, due to frailty, could have had an uncertain clinical course if operated classically. This type of hybrid procedure may prove helpful in future interventions.

\section{Supplementary material}

Supplementary material is available at https:// journals.viamedica.pl/kardiologia_polska. 


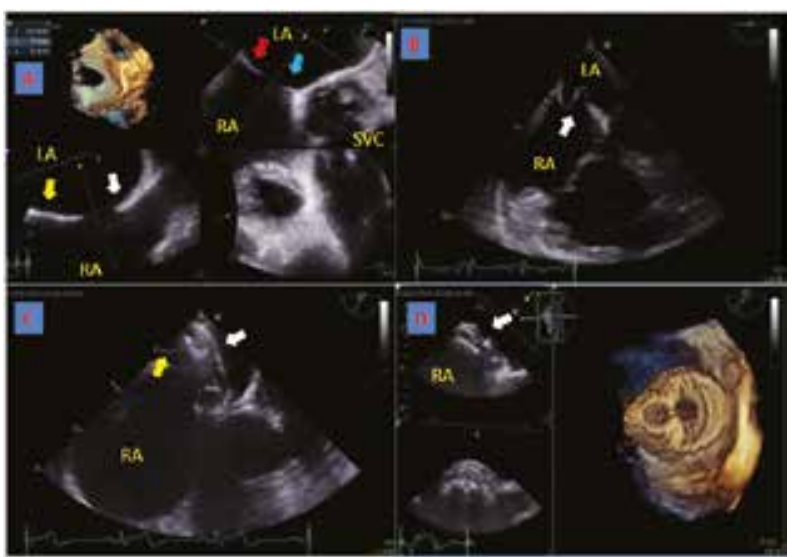

Figure 1. A. 3D reconstruction of interatrial septum with an atrial septal defect type II localized in the superior and anterior aspect of the septum. The postero-superior rim (superior vena cava rim) is absent (white arrow), the postero-inferior rim is $14 \mathrm{~mm}$ (yellow arrow), the posterior rim is $7 \mathrm{~mm}$ (red arrow), the antero-superior $\operatorname{rim}$ (aortic rim) is minimal (blue arrow $-4 \mathrm{~mm}$ ). The shape of the ASD is elliptical with diameters of 10 and $17 \mathrm{~mm}$, respectively.

B. Transesophageal echocardiography, midesophageal 4-chamber view. The white arrow points to the interatrial septal aneurysm. C. The first attempt for ASD closure. Transesophageal echocardiography: a modified mid-esophageal aortic valve view during the push test. The white arrow points to the implanted occluder device, the yellow arrow points to the interatrial septal aneurysm giving poor support to the implanted device. D. The hybrid approach. The 3D reconstruction of the implanted Lifetech Cera 20-mm occluder after it was successfully secured by a single surgical suture Abbreviations: ASD, atrial septal defect

\section{Article information}

Acknowledgments: We thank Mr Przemysław Węglarz for the support given during planning of the procedure.

\section{Conflict of interest: None declared.}

Open access: This article is available in open access under Creative Common Attribution-Non-Commercial-No Derivatives 4.0 International (CC BY-NC-ND 4.0) license, allowing to download articles and share them with others as long as they credit the authors and the publisher, but without permission to change them in any way or use them commercially. For commercial use, please contact the journal office at kardiologiapolska@ptkardio.pl.

How to cite: Przybylski R, Reczuch J, Bochenek M, et al. Hybrid percutaneous atrial septal defect closure with surgical occluder fixation. Kardiol Pol. 2021; 79(10): 1157-1158, doi: 10.33963/KP.a2021.0078.

\section{REFERENCES}

1. Baumgartner H, De Backer J, Babu-Narayan S, et al.2020 ESC Guidelines for the management of adult congenital heart disease. Eur Heart J.2021;42(6): 563-645, doi: 10.1093/eurheartj/ehaa554, indexed in Pubmed: 32860028.

2. Grygier M, Sabiniewicz R, Smolka G, et al. Percutaneous closure of atrial septal defect: a consensus document of the joint group of experts from the Association of Cardiovascular Interventions and the Grown-Up Congenital Heart Disease Section of the Polish Cardiac Society. Kardiol Pol. 2020; 78(10): 1066-1083, doi: 10.33963/KP.15629, indexed in Pubmed: 33016689. 